\title{
Piagetian Theory in Online Teacher Education
}

\author{
Danielle E. Kaplan \\ California School of Education, Alliant International University, San Francisco, United States of America \\ Email: dkaplan@alliant.edu
}

How to cite this paper: Kaplan, D. E. (2018). Piagetian Theory in Online Teacher Education. Creative Education, 9, 831-837. https://doi.org/10.4236/ce.2018.96061

Received: January 31, 2018

Accepted: May 8, 2018

Published: May 11, 2018

Copyright $\odot 2018$ by author and Scientific Research Publishing Inc. This work is licensed under the Creative Commons Attribution International License (CC BY 4.0).

http://creativecommons.org/licenses/by/4.0/

\begin{abstract}
This research involves the study of Piagetian Theory in Online Teacher Education. Piagetian theories were included in an online course in cognition and critical thinking in education as foundational psychological frameworks to apply to educational practice. Participants applied theoretical frameworks in instruction and learning design in the form of lessons and projects. Lessons and projects were analyzed for understanding and application of theory.
\end{abstract}

\section{Keywords}

Psychology, Education, Instruction, Teacher Training, Critical Thinking, Piaget

\section{Introduction}

The California School of Education at Alliant International University has included a course in Critical Thinking for Teaching and Learning in a sequence of courses designed to prepare current and future educators to develop thinkers. A previous paper (Kaplan, 2017) describes the course. Included in the course were overarching frameworks guiding design, core relevant content, poignant and significant assignments and meaningful communication. Course skill and learning outcomes include critiquing psychological theories in teaching and learning and applying theories in education.

Piaget's theories are persisting, enlightening many learners about the origins of intelligence and cognitive development (Piaget, 1952, 1964; Flavell, 1963; Nurrenbern, 2001), and providing tremendous value in application in many disciplines, including education (Kamii \& Devries, 1980; Blake \& Pope, 2008; Simatwa, 2010). The theories describe how humans construct and adapt understanding through processes of sensory and intellectual development through experience in the environment. Processes of adaptation of schema knowledge are defined as accommodation and assimilation and are underlying development of equilibrium. Human development is explained in four phases recognized by 
ability and activity from sensory to concrete to advanced abstract thinking.

The overarching objective of this research is to continue foundational understanding and application of Piagetian theory in the training of teachers. A further objective is to develop the online instructional technologies to accomplish this goal. This paper describes the participants, instruments, analysis and results of applying Piagetian theory in teacher training. The course not only teaches about Piagetian theory, but also applies it in instruction by optimizing formal operational learning with broad exposure to varying abstract thinking activities which encourage schema development of application of psychological theory to education.

\section{Guiding Design}

\subsection{Participants}

Study participants included Alliant International University California School of Education Credential and Master of Education students enrolled in Critical Thinking in Teaching and Learning over the course of several terms over two years. Twenty-one of sixty students volunteered to include their work in the study, five male and sixteen female. The participant body is made up of teachers and teachers in training on intern and student teaching tracks in special education, single subject in varying subject areas, multiple subject credentials, and Teaching English as a Second Language (TESOL). Those who agreed to participate were made up of two Multiple Subject candidates, fourteen Single Subject candidates including two in Math, two in English, three in Physical Education, two in Science, two in Language, two Educational Specialists, four undeclared, and one TESOL candidate.

\subsection{Instruments}

Study instruments were embedded into the Critical Thinking in Teaching and Learning online course Piaget Module. Participants were presented with Piagetian and Constructivism resources. Understanding and application of theory were measured in group analyses, lesson designs and group project designs received through online submissions in digital word or web format. Group analyses involved reflection on the readings, their classroom, and final project. Lesson designs required selection of a topic to teach based upon State Standards with a design incorporating the reading. Group project designs were culminating group or individual work incorporating the reading into projects to improve critical thinking.

\subsection{Analysis}

Student constructions were analyzed for theory understanding and referencing and application of theory in education. Theory discussions and analysis noted whether they acknowledged and noted theory and what they found relevant in the theory. Lesson analysis involved accounting for and describing referencing 
to theory and application of theory in lesson design. Projects were analyzed for theory referencing and application in project design.

\section{Piagetian Theory Module}

Module 3 is a unit on constructivism and Piagetian theories of psychology in critical thinking and education. The components of all Modules and Module 3 are described by Kaplan in a previous paper (2017). Module 3 is described below. The goal of the module is to provide an overview of constructivist and Piagetian theories. Learning objectives include analyzing principles of Constructivism and Piagetian theories and determining how to effectively apply the principles of Constructivism and Piagetian theories in lesson plan and project design.

Module 3 is made up of readings, forums, and assignments with embedded instruments and measures. Readings include Cooper (2013), Fosnot \& Perry (1996), Huitt \& Hummel (2003), Piaget (1952), and Piaget and Cook (1954). Each reading presents foundational theories in Constructivism and Piagetian theories. Assignments include brainstorming in project groups over how to incorporate Constructivism and Piagetian theories into project design, selecting insights from Constructivism and Piagetian theories and incorporating into lesson designed in Module 1 and 2, and providing meaningful feedback to classmates' lesson designs.

\section{Results}

\subsection{Theory Analysis and Application}

Many participants noted developmental phase as relevant to Piaget's theories and diagnosed the phase of development of the age group they teach (13). Several participants advocated phase of development be considered in determining material or circumstances within level and designing interaction for level. Several participants noted use of concrete experiences to support learning and intelligence development. One participant proposed consideration for all phases of development and what characterizes each phase from senses to objects to abstractions in all instruction. Several participants observed they were working with the preoperational stage learners and determined words and images to represent objects would be advantageous teaching strategies. Development of understanding constancy was also recognized as occurring at this age and recommended this might be supported through realizing it in different mediums. Many participants recognized they work with students in the formal operational phase and that they are developing ability to solve abstract problems beyond a logical way. They recommended designing lessons to support abstract thinking through imagining perspective, listening in pairs, and essay writing. Several participants recognized their students are in the concrete operational phase and are examining materials and issues related to logical thinking and considered presentation of objects for analytical thinking. 
Many participants mentioned individuals adapt to the environment via assimilation and accommodation and equilibrium in their balance in their analyses of the theory (11). Participants explained how individuals form schemata to represent and understand the world, and several mentioned teachers should consider how to alter student surroundings to shape schema and resources to support assimilation and accommodation. One participant suggested using model cards to visually represent concepts to support schema development. Another participant recommended teaching students about assimilation and accommodation to grow their mindset of intelligence development and hands on learning for constructing meaning.

Table 1 shows a number count for whether Piagetian theories were referenced and applied in Analyses out of twenty one participants in 20 groups. Some participants applied one or both sets of theories.

Table 1. Reference and application of theory in analyses.

\begin{tabular}{lcc}
\hline \multirow{2}{*}{\begin{tabular}{c} 
Reference and Application of $\begin{array}{c}\text { Theory } \\
\text { Theory in Analyses }\end{array}$ \\
\cline { 2 - 2 }
\end{tabular}} & $\begin{array}{c}\text { Assimilation/Accommodation/ } \\
\text { Equilibrium/Schema }\end{array}$ & Cognitive Stages of Development \\
\hline 11 & 13 \\
\hline
\end{tabular}

\subsection{Application in Lesson Designs}

Applications of Piaget's theories in lesson designs arose in relation to schema development, experience in intelligence development, and developmental phase. For example, a language and culture lesson was designed with considerations for supporting schema development by presenting resources, which enlighten culture schema. Another participant developed music and song education lessons with consideration for schema development of sound and notes. Several participants focused on hands on experience incorporated into the design to support intelligence development.

Upon reading the Piagetian resources, most participants acknowledged and designed for the developmental phase of the age group they teach or are planning to teach. Many students reported working with students potentially at the formal operational phase of development. For example, one participant focused on building formal operational level thinking in understanding the stock market by analyzing the varying effects on the market. Another participant designed a color coding system to develop abstract formal operational thinking in Chemistry. Another focused on visual aids in math. Another participant focused on formal operational thinking developed a check book balancing lesson predicting expenses. One participant designed advanced level thinking through reading and annotating of text. One participant developed a lesson around self regulating behavior in nutrition at the formal operational phase. Another participant used recall of previous experiences to support assimilation and accommodation and the formal operational level. 
Many participants reported they were working with the concrete operational phase students, preoperational to concrete operation shift students, and concrete to formal operational shift students. One participant focused on supporting students to the concrete operational phase from the preoperational phase with group interaction. One participant designed support for concrete operational thought and transition from Concrete to formal operational thinking in math with model cards, which visualize information connections. One participant designed support for preoperational and concrete operational shit with data graphing activity. Another participant designed concrete to formal operational development around publishing a newspaper. One participant focused on using varying representation methods and real life experience in a math lesson at the concrete to formal operational phase. Hands on experiences were advocated for the concrete operational phase. Consideration of whole development was recommended in physical education.

Table 2 shows a number count for whether Piagetian theories were referenced and applied in Lesson Designs out of twenty one participants. Some participants applied one or both sets of theories.

Table 2. Reference and application of theory in lesson designs.

\begin{tabular}{lcc}
\hline \multirow{2}{*}{$\begin{array}{c}\text { Reference and Application of } \\
\text { Theory in Lesson Designs }\end{array}$} & $\begin{array}{c}\text { Tssimilation/Accommodation/ } \\
\text { Equilibrium/Schema }\end{array}$ & Cognitive Stages of Development \\
\cline { 2 - 3 } & 15 & 16 \\
\hline
\end{tabular}

\subsection{Application in Project Designs}

Project designs and documentation reported application of several aspects of Piaget's theories, engagement experience in assimilation and accommodation of schema, equilibrium and assimilation and accommodation in schema development, and developmental phase considerations. Several projects considered hands on experience with opportunities for active engagement. There was consideration for student adaptation to the environment through assimilation and accommodation in balance to maintain equilibrium, and designing environments to alter surroundings for schema development with observations of how behaviors and thinking adapts. There was consideration for broader environments for play and exploration in learning than four walls of a classroom and how to extend this for example through nature walks. There was consideration for new schema development in language and culture learning, with designs for group presentations to stimulate assimilation and accommodation in equilibrium. There were designs for an interactive website for interactive exploring for assimilation and accommodation and schema development. Exploration of resources as an activity for assimilation and accommodation was also recommended.

Participant projects reported focusing on students at the preoperational, con- 
crete operational and formal operational phases of development and shifts between phases. One project design considered the pattern of cognitive development in each activity development, with sensory, concrete visual symbolic, logic, and lastly demonstrating abstract thinking through writing and analysis and demonstration. One project focused on the concrete operational phase with problems with logical analytical thinking in hands on investigative and interactive experiences. Preoperational development designs encouraged students to work in groups and pairs to discuss and listen, using relevant materials. One project reporting focus on students at the concrete operational phase in healthy eating considered portion control as a good focus for development of the law of conservation, and experience cooking seeing forms change.

One project reported to support students moving from concrete to formal operation developmental phases in project design with use of symbols for abstract concepts. One project considered supporting the formal operational phase with abstract thinking in stock market analysis, hypothesizing about gain building portfolios. Another project considered formal operations in Algebra, and supporting abstract thinking and formulating hypotheses with model cards using color coding to indicate thinking type and visualize knowledge. Another project focused on pattern and possibility exploration in article analysis and reflective abstraction. Consideration for possibilities for deeper thinking and connection in music and the arts at the formal operational phase were designed into activities developing and analyzing characters and music.

Table 3 shows a number count for whether Piagetian theories were referenced and applied in Project Designs out of twenty one participants in 20 groups. Some participants applied one or both sets of theories.

Table 3. Reference and application of theory in project designs.

\begin{tabular}{ccc}
\hline \multirow{2}{*}{$\begin{array}{c}\text { Reference and Application of } \\
\text { Theory in Project Designs }\end{array}$} & $\begin{array}{c}\text { Thsimilation/Accommodation/ } \\
\text { Equilibrium/Schema }\end{array}$ & Cognitive Stages of Development \\
\cline { 2 - 3 } & 14 & 11 \\
\hline
\end{tabular}

\section{Conclusion}

The results of the study reveal Piagetian theory to be informative to lesson and project design and the development of teachers and learners in a number of ways. Upon exposure to theories, participants noted the importance of recognizing the developmental level of the age group being taught and particular methods of supporting differences in developmental ability at varying phases. Participants recognized the importance of shaping the activities for interaction and exposure. Participants recognized the necessity of shaping the environment for schema development and assessing the state of student knowing for supporting assimilation and accommodation in schema development.

Results show participants were able to understand and reference the theories. 
It is highly likely a result of the reading resources and experiencing the discussions in the course. However, there was no pretest to test prior understanding to experiencing the course readings and module, or proof their understanding didn't come from other sources outside of the course, thus a causal claim about the effect of instruction cannot be made from this study. A future study might pretest knowledge and compare groups who have experienced the resources and groups who have not to make a causal claim about instruction. While all participants referenced and applied theory, not all participants referenced and applied all theories. The assignments could be redesigned to require this or improve in inducing everyone's referencing of all components of the theory in another way.

\section{References}

Blake, B., \& Pope, T. (2008). Developmental Psychology: Incorporating Piaget's and Vygotsky's in Classrooms. Journal of Cross-Disciplinary Perspectives in Education, 1, 59-67.

Cooper, S. (2013). Constructivism \& Discovery Learning. In Theories of Learning in Educational Psychology from Life Circles Inc.

Fosnot, C. T., \& Perry, R. S. (1996). Constructivism: A Psychological Theory of Learning. Constructivism: Theory, Perspectives, and Practice, 2, 8-33.

http://rsperry.com/wp-content/uploads/2015/10/Final-CHAPTER-2.pdf

Flavell, J. H. (1963). The Developmental Psychology of Jean Piaget. New York: Van Nostrand. https://doi.org/10.1037/11449-000

Huitt, W., \& Hummel, J. (2003). Piaget's Theory of Cognitive Development. Educational Psychology Interactive. Valdosta, GA: Valdosta State University. http://www.edpsycinteractive.org/topics/cognition/piaget.html

Kaplan, D. E. (2017). Online Teacher Training of Cognition and Learning in Education. Psychology, 8, 373-386. https://doi.org/10.4236/psych.2017.83023

Kamii, C., \& DeVries, R. (1980). Group Games in Early Education: Implications of Piaget's Theory. National Association for the Education of Young Children.

Nurrenbern, S. (2001). Piaget's Theory of Intellectual Development Revisited. Journal of Chemical Education, 78, 1107. https://doi.org/10.1021/ed078p1107.1

Piaget, J. (1952). The Origins of Intelligence in Children. New York, NY: W W Norton \& Co. https://doi.org/10.1037/11494-000

Piaget, J., \& Cook, M. (1954). The Construction of Reality in the Child. New York, NY: Basic Books. https://doi.org/10.1037/11168-000

Piaget, J. (1964). Part 1: Cognitive Development in Children: Piaget Development and Learning. Journal of Research in Science Teaching, 2, 176-186. https://doi.org/10.1002/tea.3660020306

Simatwa, E. M. W. (2010). Piaget's Theory of Intellectual Development and Its Implications for Instructional Management at Pre-Secondary School Level. Educational Research Review, 5, 366-371. 